Stereotactic
and Functional
Neurosurgery

\title{
Induction of Bradykinesia with Pallidal Deep Brain Stimulation in Patients with Cranial-Cervical Dystonia
}

\author{
Brian D. Berman ${ }^{a}$ Philip A. Starr ${ }^{b, c}$ William J. Marks, Jr. ${ }^{a, c}$ Jill L. Ostrem ${ }^{a, c}$ \\ Departments of a Neurology and ${ }^{\mathrm{b}}$ Neurological Surgery, University of California, and ${ }^{\mathrm{C}}$ Department of \\ Veterans Affairs Parkinson's Disease Research, Education, and Clinical Center (PADRECC), San Francisco, Calif., USA
}

\section{Key Words}

Dystonia - Deep brain stimulation · Globus pallidus •

Cranial-cervical dystonia $\cdot$ Bradykinesia

\begin{abstract}
Background: Deep brain stimulation (DBS) of the globus pallidus internus (GPi) is an effective and well-tolerated treatment for idiopathic generalized dystonia. More recently, it has been applied as a treatment for focal and segmental dystonias. This patient population offers an opportunity to study the effects of alteration of pallidal outflow on previously normal limb function. Methods: We sought to retrospectively characterize the extent of novel GPi DBS-induced adverse motor effects in patients with adult-onset cervical and cranial-cervical dystonia using a questionnaire, and compared the findings to dystonia improvement as measured by standard scales. Results: Despite significant improvement in dystonia (65\% in mean Burke-Fahn-Marsden Dystonia Rating Scale motor score, $p<0.005$, and $59 \%$ in mean Toronto Western Spasmodic Torticollis Rating Scale score, $p<0.008$ ), slowing and difficulty with normal motor function was reported in previously nondystonic extremities in 10 of 11 patients. Symptoms were common in both upper and lower extremities and included new difficulties with handwriting (82\%), getting up from a chair or in/out of a car (73\%), and walking (45\%), and were not associated with
\end{abstract}

aberrant lead placement near the internal capsule. Conclusion: Although GPi DBS was shown to be effective in these patients, the influence of GPi DBS on nondystonic body regions deserves further investigation.

Copyright $\odot 2009$ S. Karger AG, Basel

\section{Introduction}

Chronic bilateral deep brain stimulation (DBS) of the globus pallidus internus (GPi) for the treatment of medically refractory forms of primary generalized dystonia has been shown to be effective and well tolerated in most patients [1-3]. GPi DBS has also shown promising benefit in refractory primary focal and segmental dystonia syndromes, including cervical and cranial-cervical dystonia, in a number of small case series [2, 4-7]. Recently, we noted that a large subset of our cranial-cervical dystonia patients were reporting new difficulties with gait and fine motor activities in previously nondystonic body regions after bilateral GPi DBS [7]. Similar findings have been anecdotally reported in one prior publication involving a series of patients with primary generalized dystonia [8]. In this retrospective study, we sought to further investigate stimulation-induced motor impairments in patients with cervical and cranial-cervical dystonia, using a patient-based questionnaire. We studied the correlation of

\section{KARGER}

(C) 2009 S. Karger AG, Basel

Fax +4161306 1234

E-Mail karger@karger.ch

www.karger.com
Accessible online at:

www.karger.com/sfn
Jill L. Ostrem

University of California San Francisco

400 Parnassus Ave, Box 0138

San Francisco, CA 94143 (USA)

Tel. +1 415502 3576, Fax +1 415502 4276, E-Mail jill.ostrem@ucsf.edu 
stimulation-induced motor impairments with electrode location, and with degree of improvement in dystonia, to better understand the mechanism underlying the stimulation-induced impairments.

\section{Methods}

\section{Patients}

Eleven patients with idiopathic cervical and cranial-cervical dystonia, who had undergone bilateral GPi DBS at the University of California San Francisco Medical Center or the San Francisco Veterans Affairs Medical Center between 1998 and 2006, were considered for this study. All patients were diagnosed by a movement disorders neurologist and had normal neurological exams except for their dystonia, and none showed evidence of dystonia extending to their upper or lower extremities. None of the patients had a history of exposure to neuroleptics or another identifiable secondary cause of their dystonia.

\section{Study Design}

All study patients were clinically evaluated preoperatively and at scheduled visits after surgery using the validated Burke-FahnMarsden Dystonia Rating Scale [9] (BFMDRS) and the Toronto Western Spasmodic Torticollis Rating Scale [10] (TWSTRS). A questionnaire was designed to better characterize and evaluate the incidence and severity of any possible abnormal motor effects induced in previously unaffected limbs after bilateral DBS implantation. Patients were asked to rate changes in various upper and lower extremity motor activities (e.g. 'handwriting' and 'walking up stairs') as 'improved', 'no change', 'mildly worsened', 'moderately worsened', or 'severely worsened' compared to their preoperative baseline function. Patients were asked to record symptoms at their most severe, after their DBS was activated and stable programming settings had been achieved for at least 1 month. The severity of stimulation-induced motor impairments was quantified for statistical analyses by assigning 0 points for improved or no change in activities and 1, 2, or 3 points for mildly, moderately, or severely worsened changes, respectively.

\section{Surgery}

Patients were operated on under the Medtronic humanitarian device exemption for primary dystonia using a surgical technique to implant the DBS systems described in detail in an earlier publication [11]. The initial anatomic target was defined by direct visualization of the GPi borders on stereotactic brain MRI using inversion recovery fast spin echo imaging. Quadripolar electrode array trajectories were planned such that they traversed the intercommissural plane within the posterior GPi at a distance of 3-4 $\mathrm{mm}$ from the pallidocapsular border and terminated at the dorsolateral border of the optic tract.

All patients were implanted with bilateral DBS leads (Model 3387, Medtronic, Minneapolis, Minn., USA) under monitored local anesthesia. Single-unit microelectrode recordings were used to confirm GPi neuronal activity and to identify cells in which the discharge corresponded to passive movements of the contralateral extremities, neck, or face. Testing was performed intraoperatively to determine the voltage threshold for stimulation-induced corticobulbar or corticospinal activation. Since cells corresponding to movement of the jaw or neck were rare, the leads were placed so as to span the full body representation, including arm and leg territories. A Medtronic Kinetra dual-channel pulse generator was placed under general anesthesia, either during the DBS implantation surgery or during a second operation shortly thereafter.

\section{Determination of DBS Lead Location}

GPi placement was verified by postoperative MRI using a transmit-receive headcoil in accordance with the device manufacturer recommendations. The MR images were transferred to an image-processing station (Framelink version 4.1; Medtronic) for analysis. Lateral, vertical, and anterior-posterior coordinates of the distal tip of the DBS lead and of the entry point were measured with respect to the midcommissural point and documented $[12,13]$. In addition, the location of the lead with respect to the pallidocapsular border (edge of internal capsule) was measured on $\mathrm{T}_{2}$-weighted fast spin echo images. Measurements were made in two dimensions on the reformatted axial image passing through the commissures - a plane chosen because, following programming for optimal benefit, most active electrodes had a vertical coordinate close to $0 \mathrm{~mm}$. A straight line was drawn between the anteromedial and posterolateral corners of the GPi visualized in the plane of the commissures and considered to represent the pallidocapsular border. The distance from the lead was then measured perpendicular from the pallidocapsular border.

\section{Programming of the DBS Implant}

Neurostimulator programming was performed by a movement disorders neurologist or clinical nurse specialist 1-2 weeks after implantation. Each electrode was activated separately in a unipolar fashion, and voltage-limiting adverse effects were noted for each electrode. The most acute common stimulation-induced adverse effects noted during programming were dysarthria or tonic contraction of contralateral facial or arm muscles, presumably due to current spread to the corticobulbar or corticospinal tracts. All patients were initially programmed using one or two electrodes in unipolar mode, with pulse width of $210 \mu \mathrm{s}$, and frequency of $145-185 \mathrm{~Hz}$. The final contact choice using unipolar or bipolar mode was set at a voltage level below the threshold for acute stimulation-induced facial or arm tonic contraction, typically by at least $0.4 \mathrm{~V}$. Most patients returned for follow-up programming visits every 1-2 months. If patients were still experiencing dystonic symptoms, changes were made in contact choice, voltage, or frequency. Programming settings for each patient at the approximately 6-month follow-up visit are listed in table 1 .

\section{Statistical Analysis}

Descriptive analyses were used to report the survey results. Statistical significance of changes in clinical rating scales after surgery compared with baseline was assessed using the Wilcoxon signed-rank test (paired). Correlation between degree of improvements in dystonia rating scales seen postoperatively and degree of stimulation-induced motor impairments (assessed by calculating the numerical summation of all motor symptoms reported as an overall stimulation-induced motor impairment severity) was assessed using a Pearson correlation coefficient (two-tailed). Also, the correlation between the overall stimulation-induced motor 
Table 1. Clinical characteristics of patients at baseline and after bilateral GPi DBS

\begin{tabular}{|c|c|c|c|c|c|c|c|c|c|c|c|c|c|}
\hline \multirow[t]{2}{*}{$\begin{array}{l}\mathrm{Pa}- \\
\text { tient }\end{array}$} & \multirow[t]{2}{*}{ Sex } & \multirow{2}{*}{$\begin{array}{l}\text { Age at } \\
\text { onset } \\
\text { years }\end{array}$} & \multirow{2}{*}{$\begin{array}{l}\text { Duration } \\
\text { of illness } \\
\text { years }\end{array}$} & \multirow[t]{2}{*}{$\begin{array}{l}\text { Site of } \\
\text { onset }\end{array}$} & \multirow[t]{2}{*}{$\begin{array}{l}\text { Distribution } \\
\text { of dystonia }\end{array}$} & \multirow{2}{*}{$\begin{array}{l}\text { DBS programming } \\
\text { parameters at follow-up } \\
\text { electrodes/voltage/PW/ } \\
\text { freq. }\end{array}$} & \multirow{2}{*}{$\begin{array}{l}\text { Duration of } \\
\text { follow-up } \\
\text { months }\end{array}$} & \multicolumn{2}{|c|}{$\begin{array}{l}\text { BFMDRS total } \\
\text { motor score }\end{array}$} & \multicolumn{2}{|c|}{$\begin{array}{l}\text { BFMDRS total } \\
\text { disability score }\end{array}$} & \multicolumn{2}{|c|}{$\begin{array}{l}\text { TWSTRS } \\
\text { total score }\end{array}$} \\
\hline & & & & & & & & $\mathrm{B}$ & $\mathrm{F}$ & $\mathrm{B}$ & $\mathrm{F}$ & B & F \\
\hline 1 & F & 48 & 4 & cervical & $\begin{array}{l}\text { cranial } \\
\text { cervical/ } \\
\text { truncal }\end{array}$ & $\begin{array}{l}\mathrm{L}: \mathrm{C}+1-/ 3.6 / 210 / 185 \\
\mathrm{R}: \mathrm{C}+5-/ 3.5 / 210 / 185\end{array}$ & 3 & 22.5 & 4 & 4 & 0 & 64.5 & 21.5 \\
\hline 2 & F & 28 & 19 & cervical & cervical & $\begin{array}{l}\mathrm{L}: \mathrm{C}+2-/ 2.1 / 210 / 185 \\
\mathrm{R}: \mathrm{C}+6-/ 3.3 / 210 / 185\end{array}$ & 14 & 8 & 6 & 4 & 1 & 50.25 & 25.5 \\
\hline 3 & M & 37 & 25 & cervical & cervical & $\begin{array}{l}\mathrm{L}: \mathrm{C}+2-/ 4.0 / 210 / 185 \\
\mathrm{R}: \mathrm{C}+6-/ 4.0 / 210 / 185\end{array}$ & 7 & 6 & 1.5 & 3 & 1 & 44.25 & 3 \\
\hline 4 & F & 39 & 10 & cervical & $\begin{array}{l}\text { cranial } \\
\text { cervical }\end{array}$ & $\begin{array}{l}\mathrm{L}: \mathrm{C}+1-/ 3.5 / 210 / 145 \\
\mathrm{R}: \mathrm{C}+5-/ 3.2 / 210 / 145\end{array}$ & 2 & 10 & 1.5 & 5 & 4 & 64.5 & 8 \\
\hline 5 & F & 51 & 6 & eyes & $\begin{array}{l}\text { cranial } \\
\text { cervical }\end{array}$ & $\begin{array}{l}\mathrm{L}: \mathrm{C}+2-3-/ 3.5 / 210 / 145 \\
\mathrm{R}: \mathrm{C}+5-6-/ 3.2 / 210 / 145\end{array}$ & 6 & 16 & 10 & 5 & 2 & 48.25 & 19 \\
\hline 6 & M & 37 & 20 & cervical & $\begin{array}{l}\text { cranial } \\
\text { cervical }\end{array}$ & $\begin{array}{l}\mathrm{L}: \mathrm{C}+1-2-/ 3.7 / 210 / 185 \\
\mathrm{R}: \mathrm{C}+5-6-/ 3.8 / 210 / 185\end{array}$ & 12 & 34.5 & 3 & 8 & 3 & 44.6 & 13.5 \\
\hline 7 & M & 55 & 8 & eyes & $\begin{array}{l}\text { cranial } \\
\text { cervical }\end{array}$ & $\begin{array}{l}\mathrm{L}: \mathrm{C}+2-/ 3.6 / 210 / 185 \\
\mathrm{R}: \mathrm{C}+6-/ 3.6 / 210 / 185\end{array}$ & 9 & 16 & 4 & 3 & 3 & NA & 35 \\
\hline 8 & M & 59 & 9 & eyes & $\begin{array}{l}\text { cranial } \\
\text { cervical }\end{array}$ & $\begin{array}{l}\mathrm{L}: \mathrm{C}+2-/ 3.8 / 210 / 145 \\
\mathrm{R}: \mathrm{C}+5-6-/ 3.8 / 210 / 145\end{array}$ & 6 & 18 & 8 & 6 & 4 & 53.25 & 13 \\
\hline 9 & M & 58 & 5 & eyes & $\begin{array}{l}\text { cranial } \\
\text { cervical/ } \\
\text { truncal }\end{array}$ & $\begin{array}{l}\mathrm{L}: \mathrm{C}+2-3-/ 2.9 / 90 / 185 \\
\mathrm{R}: \mathrm{C}+5-6-/ 3.8 / 180 / 185\end{array}$ & 10 & 30 & 3 & 5 & 2 & 36.5 & 0 \\
\hline 10 & M & 47 & 5 & eyes & $\begin{array}{l}\text { cranial } \\
\text { cervical }\end{array}$ & $\begin{array}{l}\text { L: } 1-2-3+/ 5.0 / 210 / 185 \\
\text { R: } 5-6-7+/ 4.0 / 210 / 185\end{array}$ & 12 & 15 & 12.5 & 6 & 6 & 46 & 47 \\
\hline 11 & $\mathrm{~F}$ & 28 & 38 & cervical & $\begin{array}{l}\text { cranial } \\
\text { cervical }\end{array}$ & $\begin{array}{l}\mathrm{L}: \mathrm{C}+2-/ 3.5 / 210 / 130 \\
\mathrm{R}: \mathrm{C}+6-/ 3.5 / 210 / 130\end{array}$ & 6 & 9 & 11 & 3 & 5 & 61.5 & 60.5 \\
\hline $\begin{array}{l}\text { Mean } \\
( \pm S D)\end{array}$ & & $\begin{array}{l}44.3 \\
(11.2)\end{array}$ & $\begin{array}{l}13.6 \\
(10.8)\end{array}$ & & & & $\begin{array}{l}7.9 \\
(3.8)\end{array}$ & $\begin{array}{l}16.8 \\
(9.1)\end{array}$ & $\begin{array}{l}5.9 \\
(3.9)\end{array}$ & $\begin{array}{l}4.7 \\
(1.6)\end{array}$ & $\begin{array}{l}2.8 \\
(1.8)\end{array}$ & $\begin{array}{l}51.4 \\
(9.5)\end{array}$ & $\begin{array}{l}21.1 \\
(19.2)\end{array}$ \\
\hline \multicolumn{8}{|c|}{ Wilcoxon signed-rank test } & \multicolumn{2}{|c|}{$\begin{array}{l}Z=-2.80 \\
p<0.005\end{array}$} & \multicolumn{2}{|c|}{$\begin{array}{l}Z=-2.33 \\
p<0.020\end{array}$} & \multicolumn{2}{|c|}{$\begin{array}{l}Z=-2.65 \\
p<0.008\end{array}$} \\
\hline
\end{tabular}

$\mathrm{L}=$ Left; $\mathrm{R}=$ right $\mathrm{B}=$ baseline; $\mathrm{F}=$ follow up; $\mathrm{PW}=$ pulse width $(\mu \mathrm{s})$; freq. = frequency $(\mathrm{Hz}) ; \mathrm{NA}=$ not available.

impairment severity and the distance of the lead to the internal capsule was calculated using the Pearson correlation coefficient (two-tailed). Since each patient has two leads (left and right), the closest of the two lead distances to the internal capsule was used. A significance threshold of $\mathrm{p}<0.05$ was used. Statistical analyses were implemented in SPSS 12.0 for Windows (SPSS, Inc., Chicago, Ill., USA).

\section{Results}

\section{Patient Characteristics}

The clinical characteristics of the patients are summarized in table 1 . Eleven subjects ( 6 male/5 female) met the criteria for this study and completed the questionnaire. Two patients were recruited and implanted at the San Francisco Veterans Affairs Medical Center and the remainder at the University of California San Francisco Medical Center. Two patients had pure cervical dystonia and 9 patients had cranial-cervical dystonia, of which 2 had mild truncal involvement. None of the patients had any arm or leg involvement. The dystonia syndrome began with blepharospasm in 5 patients and cervical dystonia in 6 patients. The mean age of the patients when they developed initial symptoms of dystonia was $44.3 \pm 11.2$ years (range 28-59). The mean duration of disease at the time of DBS implantation was $13.6 \pm 10.8$ years (range 
Table 2. Questionnaire results evaluating novel motor effects reported after bilateral GPi DBS

\begin{tabular}{|c|c|c|c|c|c|c|c|c|c|c|c|c|}
\hline & \multicolumn{11}{|c|}{ Patient } & \multirow[t]{2}{*}{ Affected, \% } \\
\hline & 1 & 2 & 3 & 4 & 5 & 6 & 7 & 8 & 9 & 10 & 11 & \\
\hline \multicolumn{13}{|l|}{ Upper extremities } \\
\hline Lifting objects off the ground & - & ++ & ++ & ++ & - & - & ++ & - & + & + & - & 55 \\
\hline Holding objects above your head & - & + & ++ & +++ & - & - & ++ & ++ & + & - & - & 55 \\
\hline Carrying objects in your arms (such as groceries) & - & - & - & ++ & - & - & ++ & ++ & - & - & - & 27 \\
\hline Holding on to objects in your hands & - & - & - & - & - & - & ++ & + & - & - & - & 18 \\
\hline Using your fingers or hands (such as for grooming) & - & + & ++ & ++ & - & - & ++ & - & - & - & - & 36 \\
\hline Using eating utensils & - & - & ++ & - & - & - & ++ & - & - & - & - & 18 \\
\hline Dressing & - & - & ++ & ++ & - & - & ++ & - & - & + & - & 36 \\
\hline Buttoning shirts/pants & - & - & ++ & ++ & - & - & +++ & - & - & - & - & 27 \\
\hline Handwriting & - & + & +++ & +++ & + & ++ & +++ & + & ++ & +++ & - & 82 \\
\hline \multicolumn{13}{|l|}{ Lower extremities } \\
\hline Standing (including on toes or heels) & - & + & - & +++ & - & - & ++ & - & + & + & - & 45 \\
\hline Walking & - & ++ & - & ++ & - & - & ++ & - & ++ & - & - & 36 \\
\hline Walking up stairs/hills & - & +++ & + & +++ & - & - & ++ & - & + & - & - & 45 \\
\hline Walking down stairs/hills & - & ++ & - & +++ & - & - & ++ & - & + & - & - & 36 \\
\hline Walking on uneven surfaces & - & ++ & - & +++ & - & - & ++ & - & + & - & - & 36 \\
\hline Rolling over in bed & - & + & +++ & ++ & - & - & +++ & - & + & - & - & 45 \\
\hline Getting up from the floor & - & +++ & +++ & +++ & - & - & +++ & +++ & + & - & - & 55 \\
\hline Getting out of the bathtub/shower & - & ++ & +++ & + & - & - & ++ & +++ & - & - & - & 45 \\
\hline Getting up from a chair or in/out of a car & - & +++ & +++ & ++ & - & + & +++ & ++ & + & - & ++ & 73 \\
\hline
\end{tabular}

- = No change or improved; + = mildly worsened $++=$ moderately worsened $+++=$ severely worsened.

4-38). In general, patients were on little medication preoperatively because of limited effectiveness.

\section{Clinical Results}

Overall, GPi DBS resulted in dramatic improvement in the patients' dystonia symptoms (table 1). At follow-up, the BFMDRS motor scores improved from a mean of 16.8 \pm 9.1 before surgery to $5.9 \pm 3.9$ after surgery $(\mathrm{p}<0.005)$ reflecting a $65 \%$ improvement. The BFMDRS disability scores also improved from $4.7 \pm 1.6$ before surgery to 2.8 $\pm 1.8(\mathrm{p}<0.020)$. The total TWSTRS scores improved from a mean of $51.4 \pm 9.5$ at baseline to $21.1 \pm 19.2$ after surgery ( $\mathrm{p}<0.008)$, reflecting a $59 \%$ improvement in patients with cervical dystonia.

\section{Survey Results}

A summary of the responses from the questionnaire is presented in table 2. Motor side effects after GPi DBS were primarily bradykinetic in nature and frequently rated as moderately or severely worsened. The most frequently reported disturbance was a change in handwriting (82\%). Also commonly reported was difficulty lifting objects off the ground and holding objects above the head (55\%), new difficulty with getting up from a chair or in and out of a car (73\%), getting up from the floor (55\%), getting out of a tub or shower (45\%), and rolling over in bed (45\%).

\section{Correlation of Adverse Effects with Improvement in Dystonia}

Statistical analyses were performed to investigate if a relationship could be demonstrated between induced motor impairment and percent improvement (or worsening) after DBS. The numerical severity of stimulation-induced motor adverse effects were summed for patients' upper and lower extremities and plotted against the percent change in their BFMDRS motor and total TWSTRS scores (fig. 1). Although clear trends of worsening bradykinesia with improvement in dystonia rating scales were seen, the correlations did not reach statistical significance $(\mathrm{p}=0.31$ and $\mathrm{p}=0.17$ for BFMDRS motor and TWSTRS scores, respectively).

A video illustrating the motor side effects is available at http://www.karger.com/doi/10.1159/000195718.

\section{Correlation of DBS Lead Location and Degree of Motor Impairment}

Figure 2 shows an axial (left) and sagittal (right) view MRI of the brain demonstrating typical lead location within the GPi. The mean coordinates of the 22 leads at 


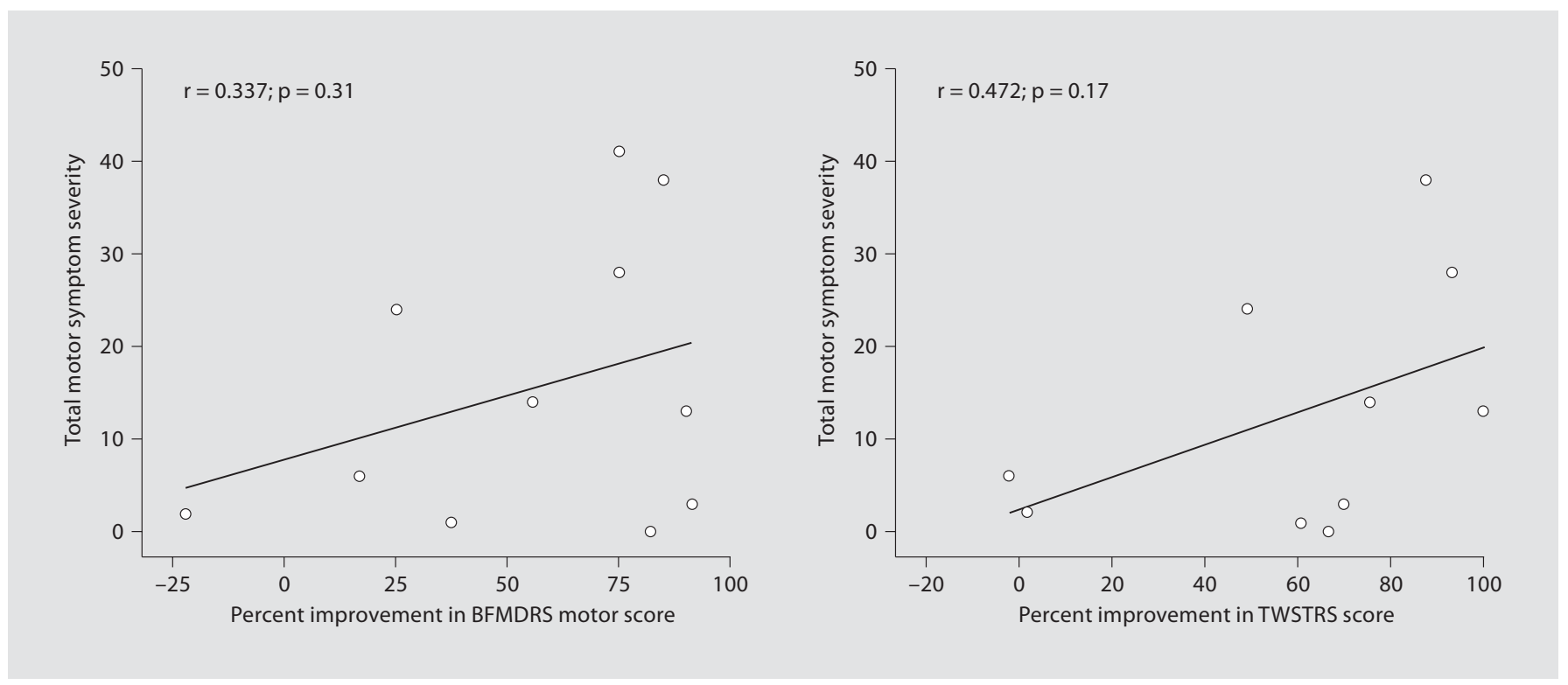

Fig. 1. Summation of extremity symptom severity scores plotted against percent improvement in BFMDRS motor and TWSTRS scores.

Fig. 2. Postoperative axial $\mathrm{T}_{2}$-weighted MRI (a) and sagittal $\mathrm{T}_{1}$-weighted MRI (b) demonstrating bilateral GPi positioning of DBS leads for the treatment of cranial-cervical dystonia.

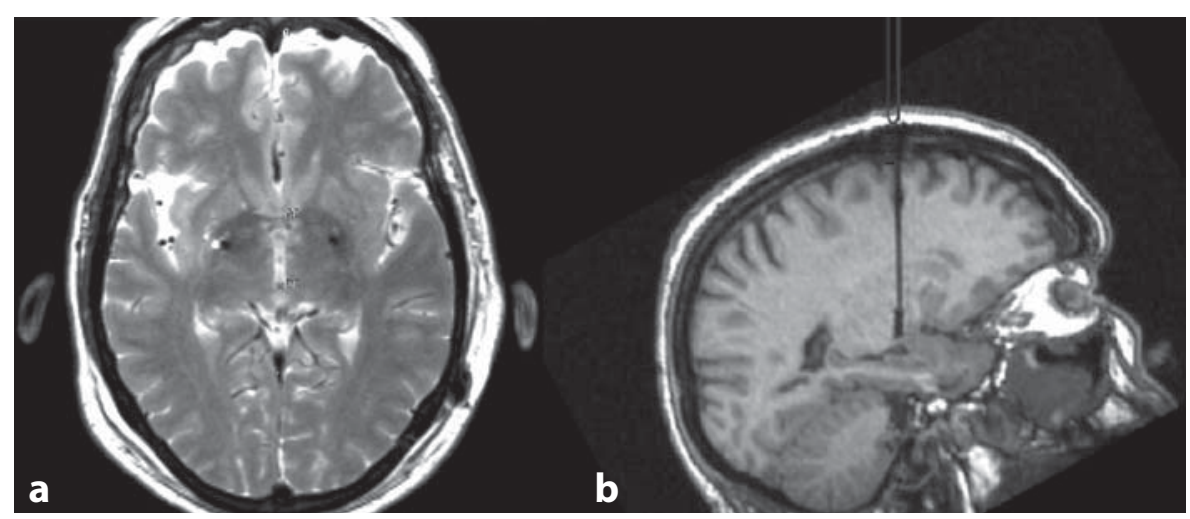

the distal tip were $20.29 \pm 1.87 \mathrm{~mm}$ lateral to the midline, $1.49 \pm 1.47 \mathrm{~mm}$ anterior to the midcommissure line, and $4.86 \pm 1.51 \mathrm{~mm}$ below the anterior-posterior commissure line (table 3 ). The bottom of contact 0 was placed at the base of the physiologically determined GPi, which is typically $0-1 \mathrm{~mm}$ dorsal to the optic tract. The mean distance from the lead to the internal capsule was $3.6 \pm 1.2$ $\mathrm{mm}$. Using the numerical summations of stimulation-induced motor symptoms as a measure of overall severity as described above, there was no significant correlation between the distance of the lead to the internal capsule and severity of stimulation-induced motor effect, although there was a trend toward a greater severity of mo- tor impairment with leads closer to the internal capsule $(\mathrm{r}=-0.377, \mathrm{p}=0.253)$ (fig. 3).

\section{DBS Parameter Adjustments}

In 10 of the 11 patients, attempts were made to find optimal DBS settings that maintained benefit for their dystonia while reducing induction of bradykinesia. Adjustments in voltage and pulse width were made to reduce the likelihood of spread to capsular regions, as well as stimulating more ventrally located contacts, to potentially avoid stimulation near the leg representation in the GPi (which is dorsal and medial to the arm representation) [14]. In general, these attempts were unsuccessful in im- 
Table 3. Lead locations (in $\mathrm{mm}$ ) from the midcommissural point and distance from active contact to internal capsule

\begin{tabular}{|c|c|c|c|c|c|c|}
\hline & \multicolumn{3}{|c|}{ Lead tip coordinates } & \multicolumn{2}{|c|}{ Lead approach angles ${ }^{1}$} & \multirow{2}{*}{$\begin{array}{l}\text { Active } \\
\text { contact to IC }\end{array}$} \\
\hline & lateral & AP & vertical & coronal plane & sagittal plane & \\
\hline Mean & 20.29 & 1.49 & -4.86 & 0.53 & 32.44 & 3.6 \\
\hline SD & 1.87 & 1.47 & 1.51 & 4.10 & 8.30 & 1.2 \\
\hline
\end{tabular}

IC = Internal capsule; $\mathrm{AP}=$ anteroposterior; $\mathrm{SD}=$ standard deviation.

${ }^{1}$ Approach angles are in degrees with respect to vertical.

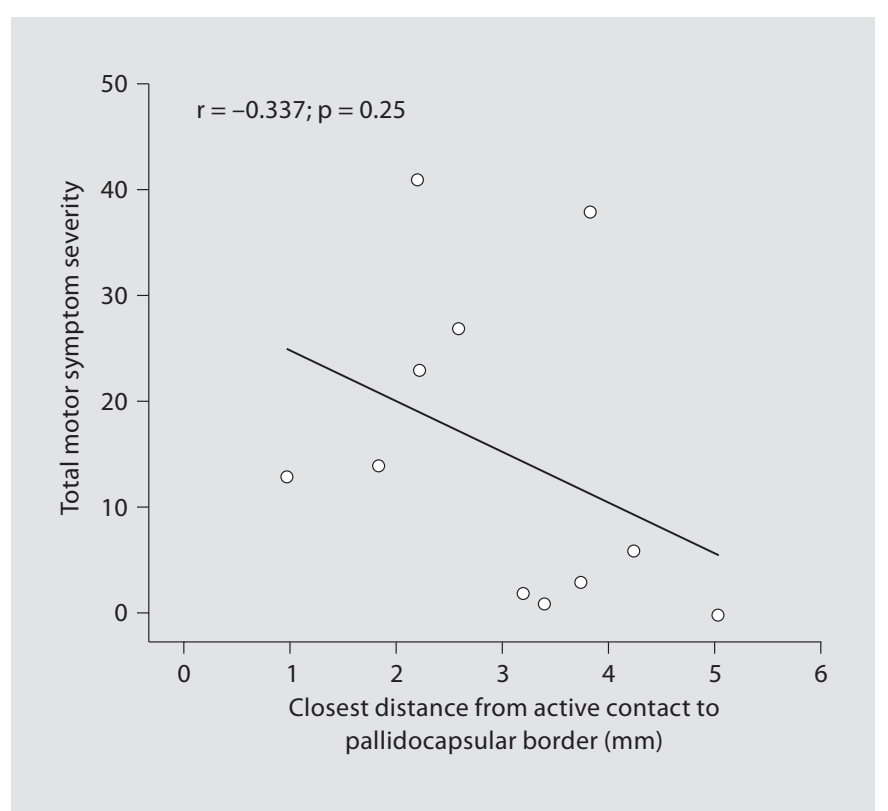

Fig. 3. Distance from the closest of the two active lead contacts to the pallidocapsular border plotted against summation of symptom severity scores.

proving the bradykinetic symptoms while maintaining the control of dystonia.

In addition, trials of lower-frequency stimulation (60$130 \mathrm{~Hz}$ ) were attempted. Lower-frequency stimulation improved the bradykinetic motor symptoms in 9 of the patients, but in 8 patients it resulted in significant worsening of their cranial and cranial-cervical dystonia, leading to titration back to a higher frequency setting and ultimately resulting in some level of compromise between improvement in dystonia and stimulation-induced adverse effects, usually around $110 \mathrm{~Hz}$.

\section{Discussion}

In this retrospective study of patients successfully treated with bilateral pallidal DBS for idiopathic cranial and cranial-cervical dystonia, we found that novel motor impairment occurred quite frequently. The motor impairments were largely bradykinetic in nature, with patients frequently reporting a moderate to severe worsening in a number of activities involving both upper and lower extremities that were previously unaffected by dystonia and felt to be normal at baseline. All patients experienced a major reduction in their cervical or cranial-cervical dystonia, but the motor impairments could not be completely dissociated from the beneficial effects on dystonia by programming changes.

During intraoperative testing and programming of GPi stimulators, the most common stimulation-induced adverse motor effects are dysarthria and tonic contraction of contralateral muscle groups in the face and arm $[1,2]$. These effects occur immediately following programming, are reversible with a modest decrease in stimulation settings or adjustment in electrode choice, and are thought to result from spread of stimulation to the corticobulbar tract or corticospinal tract. In contrast, the motor changes we report here were primarily bradykinetic in nature. There are several reasons to believe the effects were not caused by spread of stimulation to the corticobulbar tract or corticospinal tract. First, in some of our patients the symptoms developed insidiously, in 1 case after 3 years of stimulation, rather than immediately following device activation (online supplementary video, www.karger.com/doi/10.1159/000195718). Also, based on our measurements of electrode location, stimulationinduced bradykinesia is not explained by aberrant DBS lead location outside of the GPi and did not significantly correlate with distance of the lead from the internal cap- 
sule. The DBS lead tips were all placed in the posterior ventral portion of the GPi such that the corticobulbar tract fibers running medially are closest to the lead, followed more posteriorly by the corticospinal tract fibers to the arm, and even more posteriorly by the corticospinal tract fibers to the leg. As such, if the stimulation-induced bradykinesia were due to current spread to the pyramidal tracts, the first symptoms experienced would more likely anatomically correspond to the face, and in fact dysarthria is almost always the first symptom to occur acutely with spread of stimulation to the internal capsule. The patients in this study, however, were deliberately programmed at a voltage level lower than the threshold for dysarthria or tonic facial contraction, and patients who complained of lower extremity symptoms did not report facial symptoms.

Further, patients with the most benefit in dystonic symptoms tended to have the most difficulty with stimulation-induced bradykinesia suggesting that stimulationinduced bradykinesia may arise from the same neural circuit mediating the antidystonic effect rather than from a neighboring structure. Finally, using a current diffusion model to evaluate the effect of extracellular stimulation on the activation of neurons, McIntyre et al. [14] found that at $3.0 \mathrm{~V}, 100 \mu \mathrm{s}$ and $150 \mathrm{~Hz}$, neurons greater than about $2.5 \mathrm{~mm}$ from the active electrode contact do not depolarize. Although our stimulation parameters on average were slightly higher than those used in the model by McIntyre, spread of current sufficient to cause widespread capsular activation at the mean distance of 3.6 $\mathrm{mm}$ between active contact and the border of the internal capsule seems unlikely.

Others have reported isolated cases of hypokinetic motor affects following GPi stimulation in nonparkinsonian disorders, including worsening of bradykinesia in a patient with Huntington's disease at high stimulation frequencies [15] and the unilateral impairment of rapidly alternating movements in a patient treated with unilateral GPi DBS for severe Gilles de la Tourette syndrome [16]. Tisch et al. [8] reported the development of delayedonset akinesia with gait slowing, difficulty rising from a chair, and turning in bed in 2 patients treated with bilateral GPi DBS for primary generalized dystonia. Inactivation of the GPi in normal nonhuman primates has been shown to decrease the amplitude and speed of arm movements [17-19].

Recently, several small series and a few case reports have reported subthalamic DBS as a possible treatment for primary and some secondary forms of dystonia [2023]. Based on animal studies, surgical alteration of the indirect pathway alone would be expected to have fewer bradykinetic side effects than alteration of the direct and indirect pathways combined, but this remains to be demonstrated in humans $[24,25]$.

In patients with juvenile-onset primary generalized dystonia, Alterman et al. [26] found that $60-\mathrm{Hz}$ stimulation effectively treated dystonia symptoms. In our group of patients with adult-onset cervical and cranial-cervical dystonia, reducing stimulation frequency to $60 \mathrm{~Hz}$ eliminated bradykinetic adverse effects, but in almost all our patients this was associated with an unacceptable worsening of dystonia symptoms. Interestingly, as the frequency was slowly titrated up to $100-110 \mathrm{~Hz}$, many of our patients had partial relief of dystonia without a significant induction of bradykinesia, possibly reflecting a frequency range where a compromise between improvement in dystonia and induction of bradykinetic effects could be achieved. Further study of a frequency-dependent relationship between improvement in dystonia and adverse motor effects in this patient population may contribute to our understanding of the mechanism of DBS that has already been revealed by stimulation frequency changes in other movement disorders [27].

This study has a number of limitations, including our use of a subjective, nonvalidated questionnaire, which sought patient information in a retrospective manner and is therefore subject to recall bias. Moreover, although patients' descriptions of symptoms generally suggested bradykinesia, some of the induced motor symptoms may not be purely from bradykinesia and instead could be the result of other induced motor effects such as rigidity, micrographia, or incoordination. Given the overall general satisfaction and dystonia improvement with GPi DBS, there also exists a potential for patients to underreport side effects. Objective measures of bradykinetic symptoms (such as comparing performances on specified motor tasks) are critical to better characterize and quantify changes. In future studies, it would be interesting to see if a relationship exists between degree of motor impairment and the time point a patient develops stimulationinduced symptoms. Rater- and subject-blinded testing would also greatly improve the validity of any future studies.

In conclusion, GPi DBS appears to be a safe and effective therapy for focal and segmental forms of dystonia, including cervical and cranial-cervical dystonias. However, GPi stimulation in these patients may induce bradykinetic symptoms in previously unaffected limbs leading to difficulty with important motor tasks such as writing, 
getting up from a chair or in/out of a car, and walking. Although these symptoms may be somewhat improved with alteration of stimulation parameters (frequency), they usually cannot be entirely eliminated without worsening of dystonia.

\section{Acknowledgements}

This work was supported in part by NIH K08 NS002201, and by the Parkinson's Disease Research, Education, and Clinical Center (PADRECC) at the San Francisco Veterans Affairs Medical Center. We thank Monica Volz, RN, MS and Susan Heath, RN, MS for help with patient management.

\section{References}

1 Vidailhet M, Vercueil L, Houeto JL, Krystkowiak P, Benabid AL, Cornu P, Lagrange C, Tezenas du Montcel S, Dormont D, Grand S, Blond S, Detante O, Pillon B, Ardouin C, Agid Y, Destee A, Pollak P: Bilateral deepbrain stimulation of the globus pallidus in primary generalized dystonia. N Engl J Med 2005;352:459-467.

-2 Kupsch A, Benecke R, Muller J, Trottenberg T, Schneider GH, Poewe W, Eisner W, Wolters A, Muller JU, Deuschl G, Pinsker MO, Skogseid IM, Roeste GK, Vollmer-Haase J, Brentrup A, Krause M, Tronnier V, Schnitzler A, Voges J, Nikkhah G, Vesper J, Naumann M, Volkmann J: Pallidal deep-brain stimulation in primary generalized or segmental dystonia. N Engl J Med 2006;355:1978-1990.

$\checkmark 3$ Coubes P, Cif L, El Fertit H, Hemm S, Vayssiere N, Serrat S, Picot MC, Tuffery S, Claustres M, Echenne B, Frerebeau P: Electrical stimulation of the globus pallidus internus in patients with primary generalized dystonia: long-term results. J Neurosurg 2004;101: 189-194.

4 Yianni J, Bain P, Giladi N, Auca M, Gregory R, Joint C, Nandi D, Stein J, Scott R, Aziz T: Globus pallidus internus deep brain stimulation for dystonic conditions: a prospective audit. Mov Disord 2003; 18:436-442.

5 Krauss JK, Loher TJ, Pohle T, Weber S, Taub E, Barlocher CB, Burgunder JM: Pallidal deep brain stimulation in patients with cervical dystonia and severe cervical dyskinesias with cervical myelopathy. J Neurol Neurosurg Psychiatry 2002;72:249-256.

-6 Hung SW, Hamani C, Lozano AM, Poon YY, Piboolnurak P, Miyasaki JM, Lang AE, Dostrovsky JO, Hutchison WD, Moro E: Long-term outcome of bilateral pallidal deep brain stimulation for primary cervical dystonia. Neurology 2007;68:457-459.

7 Ostrem JL, Marks WJ Jr, Volz MM, Heath SL, Starr PA: Pallidal deep brain stimulation in patients with cranial-cervical dystonia (meige syndrome). Mov Disord 2007;22: 1885-1891.

$>8$ Tisch S, Zrinzo L, Limousin P, Bhatia KP, Quinn N, Ashkan K, Hariz M: Effect of electrode contact location on clinical efficacy of pallidal deep brain stimulation in primary generalised dystonia. J Neurol Neurosurg Psychiatry 2007;78:1314-1319.
-9 Burke RE, Fahn S, Marsden CD, Bressman SB, Moskowitz C, Friedman J: Validity and reliability of a rating scale for the primary torsion dystonias. Neurology 1985;35:73-77.

10 Comella CL, Stebbins GT, Goetz CG, Chmura TA, Bressman SB, Lang AE: Teaching tape for the motor section of the Toronto Western Spasmodic Torticollis Scale. Mov Disord 1997;12:570-575.

11 Starr PA, Turner RS, Rau G, Lindsey N, Heath S, Volz M, Ostrem JL, Marks WJ Jr: Microelectrode-guided implantation of deep brain stimulators into the globus pallidus internus for dystonia: techniques, electrode locations, and outcomes. J Neurosurg 2006; 104:488-501.

12 Starr PA, Christine CW, Theodosopoulos PV, Lindsey N, Byrd D, Mosley A, Marks WJ Jr: Implantation of deep brain stimulators into the subthalamic nucleus: technical approach and magnetic resonance imagingverified lead locations. J Neurosurg 2002;97: 370-387.

13 Starr PA: Placement of deep brain stimulators into the subthalamic nucleus or globus pallidus internus: technical approach. Stereotact Funct Neurosurg 2002;79:118-145.

14 McIntyre CC, Grill WM, Sherman DL, Thakor NV: Cellular effects of deep brain stimulation: model-based analysis of activation and inhibition. J Neurophysiol 2004;91: 1457-1469.

-15 Moro E, Lang AE, Strafella AP, Poon YY, Arango PM, Dagher A, Hutchison WD, Lozano AM: Bilateral globus pallidus stimulation for Huntington's disease. Ann Neurol 2004;56:290-294.

16 Diederich NJ, Kalteis K, Stamenkovic M, Pieri V, Alesch F: Efficient internal pallidal stimulation in Gilles de la Tourette syndrome: a case report. Mov Disord 2005;20: 1496-1499.

17 Mink JW, Thach WT: Basal ganglia motor control. 1. Nonexclusive relation of pallidal discharge to five movement modes. J Neurophysiol 1991;65:273-300.
18 Wenger KK, Musch KL, Mink JW: Impaired reaching and grasping after focal inactivation of globus pallidus pars interna in the monkey. J Neurophysiol 1999;82:20492060.

19 Inase M, Buford JA, Anderson ME: Changes in the control of arm position, movement, and thalamic discharge during local inactivation in the globus pallidus of the monkey. J Neurophysiol 1996;75:1087-1104.

20 Chou KL, Hurtig HI, Jaggi JL, Baltuch GH: Bilateral subthalamic nucleus deep brain stimulation in a patient with cervical dystonia and essential tremor. Mov Disord 2005; 20:377-380.

21 Sun B, Li D, Sun C: Target selection for primary dystonia deep brain stimulation: GPI or STN. Proc Am Soc Stereotact Funct Neurosurg Quadrennial Meet, New York, 2003, p 91.

22 Zhang JG, Zhang K, Wang ZC, Ge M, Ma Y: Deep brain stimulation in the treatment of secondary dystonia. Chin Med J (Engl) 2006; 119:2069-2074.

23 Kleiner-Fisman G, Liang GS, Moberg PJ, Ruocco AC, Hurtig HI, Baltuch GH, Jaggi JL, Stern MB: Subthalamic nucleus deep brain stimulation for severe idiopathic dystonia: impact on severity, neuropsychological status, and quality of life. J Neurosurg 2007;107: 29-36.

$>24$ Soares J, Kliem MA, Betarbet R, Greenamyre JT, Yamamoto B, Wichmann T: Role of external pallidal segment in primate parkinsonism: comparison of the effects of 1-methyl-4-phenyl-1,2,3,6-tetrahydropyridine-induced parkinsonism and lesions of the external pallidal segment. J Neurosci 2004;24:64176426.

25 Zhang J, Russo GS, Mewes K, Rye DB, Vitek JL: Lesions in monkey globus pallidus externus exacerbate parkinsonian symptoms. Exp Neurol 2006;199:446-453.

26 Alterman RL, Miravite J, Weisz D, Shils JL, Bressman SB, Tagliati M: Sixty hertz pallidal deep brain stimulation for primary torsion dystonia. Neurology 2007;69:681-688.

27 Birdno MJ, Grill WM: Mechanisms of deep brain stimulation in movement disorders as revealed by changes in stimulus frequency. Neurotherapeutics 2008;5:14-25. 